\title{
Reducing the spread of artemisinin resistant malaria through community-level directly observed therapy in Western of Cambodia
}

\author{
Chy Say ${ }^{1 *}$, Sokomar Nguon', Soley Lek Dy ${ }^{2}$, Kheang Soy Ty ${ }^{1}$ \\ From Challenges in malaria research \\ Basel, Switzerland. 10-12 October 2012
}

\section{Background}

Artemisinin resistant parasites have been documented recently in the Cambodia-Thailand border area, which has been the epicenter of parasite resistance to antimalarials in the past. In September 2010, the USAID funded Malaria Control in Cambodia (MCC) project, in collaboration with National Malaria Control program (CNM) and with technical and financial support from WHO, conducted community Day- 3 surveillance for Pf $(+)$ to gather evidence of drug resistance in the area. From June, 2011, the community surveillance expanded follow up to Day-28.

\section{Methods}

Twenty-six village malaria workers (VMWs) were trained on malaria screening and treatment through directly observed therapy (DOT). VMWs use RDT for all suspected malaria cases on Day-0, smears on Day-0 and Day-3, filled the case investigation form, and completed follow up on days 1-3, Day-7, and Day-28 if Day$3(+)$. Both malaria smears are sent to the health center laboratory for reading on Day-3. Malaria patients are treated with DHA-PIP for three days with DOT. An SMS alert system is sent to a higher level if Day-3(+) is confirmed by lab staff. Cases identified positive on Day7/Day-28 are referred for second line treatment with Quinine +Tetracycline for 7 days.

\section{Results}

Between June 2011 and June 2012, 327 Pf positive cases were enrolled by VMWs. Over half (54\%) were adult males between the ages of $15-49$ years. A quarter $(22 \%)$

${ }^{1}$ USAID Control and Prevention of Malaria Project, University Research Co. LLC, Phnom Penh, Cambodia

Full list of author information is available at the end of the article were mobile and migrant workers. Twenty-seventy out of 327 cases (9\%) remained positive on Day-3 and received further investigation and treatment. In addition, one case remained positive on Day-7, and 8 cases (30\%) were positive on Day-28 as detailed in Table 1. The proportion of Day-3(+) cases decreased dramatically in the second phase of the pilot.

Early warning signs of drug resistance detected by VMWs should be treated with second line treatment at the health facility, but only three referred cases were accepted for $2^{\text {nd }}$ line treatment. A challenge to seven-day treatment with Quinine + Tetracycline is the accessibility of health facilities. The CNM decided to implement other interventions such as IRS, FSAT, and screening surrounded index cases but they also have challenges.

\section{Conclusion and discussions}

This pilot proves that malaria community DOT and follow up is vital to reduce the spread of potential multi-drug resistance. Identification of early warning signs of drug resistance and treatment by DOT for first line and second line by VMWs is a feasible approach. To ensure high quality results, strong monitoring, supervision, real-time feedback results are needed. Further discussion is needed to: (1) develop a comprehensive strategy to expand surveillance on a large scale including improving malaria case management and follow-up, (2) develop harmonized

Table 1 Pf malaria cases enrolled in Tasanh health center catchment area on Day-0 to Day-28

\begin{tabular}{lcccc}
\hline Time frames & D0 & D3 (\%) & D7 (\%) & D28 (\%) \\
\hline Sep 2010-May 2011 & 200 & $48(24 \%)$ & n/a & n/a \\
Jun 2011-Jun 2012 & 327 & $27(9 \%)$ & $1(4 \%)$ & $8(30 \%)$ \\
Total & 527 & $75(15 \%)$ & & \\
\hline
\end{tabular}


guidelines for promoting cross-border treatment and contact tracing, and (3) simplify the strategy for second line treatment and screening surrounding an index case.

\section{Acknowledgements}

These results would not have been possible without the support from CNM, USAID, WHO, and other stakeholders.

\section{Author details}

${ }^{1}$ USAID Control and Prevention of Malaria Project, University Research Co.

LLC, Phnom Penh, Cambodia. ${ }^{2}$ National Malaria Control Program, Cambodia.

Published: 15 October 2012

doi:10.1186/1475-2875-11-S1-P86

Cite this article as: Say et al:: Reducing the spread of artemisinin

resistant malaria through community-level directly observed therapy in Western of Cambodia. Malaria Journal 2012 11(Suppl 1):P86.

Submit your next manuscript to BioMed Central and take full advantage of:

- Convenient online submission

- Thorough peer review

- No space constraints or color figure charges

- Immediate publication on acceptance

- Inclusion in PubMed, CAS, Scopus and Google Scholar

- Research which is freely available for redistribution

Submit your manuscript at www.biomedcentral.com/submit 